\title{
Reflective teaching of an in-service EFL teacher to improve a professional skill
}

\author{
Rosalina $^{1}$, Herri Mulyono ${ }^{2}$, Nita Kania Dewi ${ }^{3}$ \\ \{ ocalinaoca@gmail.com $\left.{ }^{1}\right\}$ \\ ${ }^{1,2,3}$ Universitas Muhammadiyah Prof. DR. Hamka, Indonesia
}

\begin{abstract}
This preliminary study was aimed to explore the perceptions of English as a foreign language (EFL) teacher about watching his of own performance on video. The primary objective of this study was to gain an in-depth understanding of video-based reflection influences teacher development. The qualitative data was gathered through a reflective journal and semi-structured interview of an in-service EFL teacher, which the data analyzed using the thematic analysis. The result yielded that video-based reflection is a valuable component as self-evaluation to assist the teacher in being aware in the teaching program. Reflecting through video helped the teacher to gain a new perspective and define the teacher's strengths and weakness in real situations. Overall, video-based reflection may have a positive effect on the teacher to enhance professional development.
\end{abstract}

Keywords: Reflection, in-service teacher, English as a foreign language, video-based reflection, teacher change.

\section{Introduction}

Reflection is a component as self-evaluation to observe someone's strengths and weaknesses, which is interrelated in thinking and movement. According to Dewey (1910, p. 6) cited in [1], reflection is a component in learning process and it can be defined as the "active, persistent, and careful consideration of any belief or supposed form of knowledge in light of the grounds that support it and the further conclusions to which it tends". Along with this growth, Schön (1987) stated that reflection promotes the development of the value of teachers in their classrooms.

In the last 25 years, José, Marcos, Sánchez, \& Tillema (2009) defines that reflection has been investigated expansively in numerous studies. Despite this, several national teacher authorizations in the worldwide, such as the National Council for Accreditation of Teacher Education (USA), the Department for International Development (UK), and the Teacher Registration Board (Australia). Those teachers involve the reflective practice as the fundamental component in influencing the quality of the teachers in several approaches, including in the teacher program and or teacher itself ([4]. With this regard, the primary aim of reflection is naturally needed for in-service teachers around the world, because the reflection will help the teachers to emphasize the awareness of the teachers itself.

The objective of this study is to explore the perception of English as a foreign language (EFL) in-service teacher after watching a video recording of his teaching. With this regard, there is primary concern of this study to address these following questions: (1) What are the EFL in-service teachers perception in watching their self-video recording in their teaching program? (2) Does video recording help EFL in-service teachers improve their teaching skills during the teaching program? The primary aim of this study is to assist the teacher in 
observing his performance in order to improve his teaching quality in the classroom. Tripp \& Rich (2012) examines that an initial purpose of reflection is to develop the teachers' quality.

\section{Previous Studies}

Three of study has been mainly interested in exploring the teachers' perceptions of using video-based reflection in teaching program [4]-[6]. First, Tripp \& Rich (2012) the study examined an in-depth understanding of how video influenced the process of teacher change in teaching programs. There were seven participants from in-service EFL teachers. The participants consist of three Special Ed teachers, two Religious Ed teachers, and two English teachers. Indeed, the researcher collected the qualitative data through several instruments such as; observations, interview, and artifacts.

The outcome reported the advantages of using video-based reflection that helped the teachers in this following objectives: (a) emphasise their evaluation, (b) monitor their teaching from a new perspective, (c) trust the feedback they received, (d) feel accountable for changing their teaching, (e) remember to enforce the changes, and (f) see their progress. As a result, the study revealed a significant impact on how the video of teaching can be used to encourage teacher improvement in the classroom.

Similarly, Baecher et al., (2013) examined the benefit of video on teachers' candidates to assess their teaching performance in early fieldwork. There were 31 participants from the public college of education in a Master's degree program of TESOL which separated into two divisions: First, sixteen participants observed their teaching through video recording and fifteen participants through rubric evaluation and supervisor's feedback. Additionally, reflective journals, observation rubric, and supervisor's score were used to gather the whole data.

As a result, the two groups showed a different result. The first group which reflected through video presented that using video for identifying the strengths and weaknesses of the teaching is a great instrument. The teachers' candidates mentioned that they felt comfortable sharing their teaching anxiety during learning and sharing their enthusiasm for better performance in the next teaching after observing themselves on video. In contrast, the group that was assessed through rubric evaluation did not share any significance because they only read the supervisor's description of the evaluation outcomes. Overall, the prospective teachers have shown that applying video-based reflection will have beneficial effects of the teacher change in the future.

Furthermore, Kleinknecht \& Schneider (2013) explored the teachers' perceptions of their awareness, emotion, and motivation after viewing their teaching and others' teaching. This study involved ten eighth-grade mathematics teachers who have experience in teaching. Then, the approach of this study was a quantitative approach which was supported by using a self-report questionnaire with rating scales. The outcome presented that the teachers gave more attention to the learning process of other teachers and activities of students or teachers while more mostly in their teaching. Furthermore, analyzing videos from other teachers helped the teachers to develop the emotional and motivational rather than analyzing videos of one's teaching. The findings suggested that watching other teaching videos may be beneficial for teachers as self-reflection and learning instrument to gain new teaching techniques from other teachers.

The study above has shown several signs of using video-based reflection in teaching. (1) The teacher's candidates were more aware to recognize the strength and weakness of their performances, 2) they obtained new perspectives from peers and supervisor's feedback for 
better performance, 3) improve the teaching quality. With this regard, Tripp \& Rich (2012) mentioned that video-based reflection has an essential effect on how video teaching can be used to encourage teacher improvement in the classroom.

Similarly, Baecher et al. (2013) highlighted that the prospective teachers felt comfortable expressing their teaching anxiety during learning and sharing their passion for better presentation in the next performance. Then, the teachers declared that applying video-based reflection will have beneficial effects of the teacher change in the future.

Additionally, Kleinknecht \& Schneider (2013) pointed out that assessing videos from other teachers enabled teachers to gain the emotional and motivational of the teacher, rather than assessing videos of one's teaching. The findings indicated that viewing other teaching videos might be essential for teachers to improve new teaching strategies from other teachers as self-reflection and learning tools.

Overall, this study offers an exciting chance for the teacher to evaluate themselves through video recording. The leading signs of this study that is reflecting through video will help the in-service teachers in acknowledging their strength and weakness in enhancing teacher performance in the classroom.

\section{Research Methodology}

\subsection{Design and Participants}

In this present study, a qualitative method was conducted to obtain insight into the perceptions of in-service teacher after viewing his video recording. Afterward, the narrative survey was carried out in this research because the researcher was interested in bringing the personal experience of the teacher.

Correspondingly, Bell, (2010) p.21 claimed that narrative research is a strategy that includes a reflective autobiography, a personal story, or the incorporation of stories from the respondent to illustrate the theme that the researcher has developed. The current study was therefore carried out from May to June 2019. Reflective and semi-structured interviews were used to gain information. As a result, this study lasted about a month to achieve all the data.

This research was attended by an EFL in-service teacher who taught English as a foreign language at secondary school. The participant was selected through the purpose of sampling. In this regard, Robinson (2014) stated that sampling techniques are non-random methods for ensuring that specific categories of instances within the sampling universe were identified in the final sample of the study.

In this regard, Mr. Niko is the participant who participated in this study. He has been teaching for about ten years. He taught English at high school junior in Jakarta. In essence, the teacher who satisfied the selection requirements was recognized by two primary considerations: (1) an English teacher in secondary school teacher who teaches in Jakarta, and (2) a teacher who volunteered to participate in this study. 


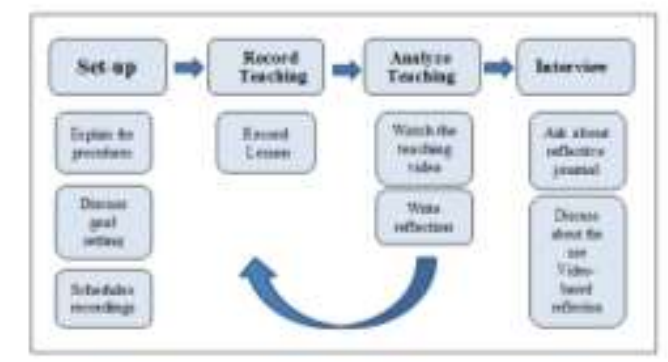

Fig.1. The procedure of the research

The method for this present study has been adapted from Tripp \& Rich (2012). In order to explain the process from the beginning, the researcher described to the participant the processes and the advantages of this study. Afterward, the researcher also requested a schedule for the participants to record the teaching activities. The participant was asked to watch their teaching video, which was recorded earlier, and also the teacher asked to write a reflective journal after watching the teaching recording. The researcher also explained to the participant that he would be interviewed at the end of the program. In an attempt to make the respondent feel as comfortable as possible, the interviewer questioned the available time of the teacher to do the interview.

The researcher had three times taken a teaching video from the participant. The videobased reflection approach was chosen because several studies have identified the advantages of using video-based reflection in collecting the data ( e.g., Christ et al., 2017; Endacott, 2016; Kleinknecht \& Schneider, 2013; Zulaiha \& Mulyono, 2018). For instance, Kleinknecht \& Schneider (2013) claimed that video-based reflection was an aspect of monitoring several movements in the teaching process in details. The following step will be taken by the EFL inservice teacher to watch their video recording and write a reflective journal for each video.

For example, Kleinknecht \& Schneider (2013) indicated that video-based reflection was a feature of overseeing the several movements in the teaching process. The next section was required the EFL In-Service Teacher to watch his video recordings and write a reflective journal for each video.

In the end, the researcher conducted a semi-structured interview for the participant. The interview question was adapted from several researchers, such as [4], [12]-[14]. After reviewing the teaching video three times, the researcher established a semi-structured interview with the participant.

Accordingly, Bell (2010) indicated that one of the essential benefits of the interview is flexible. In addition, the interview could also investigate the ideas in-depth, and respondents could show voice, facial expression, and so on to provide information that the questionnaire never does.

The interview persisted for around 20 minutes. The interview used to understand how the use of video-based reflection influenced the teaching process, which encouraged the teacher to enhance their teaching quality. The participant was flexible to discuss extra points of concern. The interview information and the reflective journal will be processed through a thematic analysis. Braun \& Clarke (2008) therefore indicated that thematic analysis is a technique for identifying, analyzing and reporting trends in detail. It organizes and explains the information in detail. 
In this present study, qualitative data were evaluated through thematic content analysis, which engaged the textual analysis of the reflective journals and the response of teachers in a semi-structured interview. Furthermore, this study adapted the content analysis from Tripp \& Rich (2012), which has relevant codes, as presented in Table 3 below.

Table 1. Two essential topics for teacher growth

\begin{tabular}{|l|l|}
\hline Recognize the need to change & $\begin{array}{l}\text { Obtain a different viewpoint } \\
\text { Specific Concern }\end{array}$ \\
\hline Implement Ideas & $\begin{array}{l}\text { Real Situations } \\
\text { Observing in multiple times }\end{array}$ \\
\hline
\end{tabular}

\section{Findings And Discussion}

The objective of this study was to explore the perceptions of the teacher after watching his teaching video. With this regarding, the teacher emphasized that the video-based reflection was valuable for the growth of teachers. The result has revealed about the movement of teacher change in these following steps: (a) Gain a different viewpoint (b) Specific concerned (c) Real situations (d) Observing in multiple times.

\subsection{Recognize the need to change}

In these following sections, the teacher indicated several points of view from his experiences while reflecting through video. Firstly the teacher yielded that video-based reflection was valuable in order to analyze the own teaching performance because the teacher was gained a new perspective after watching himself on video. Then, the video helped the teacher to comment on a specific part to gain a focused analysis of the teacher. The teacher has a great chance to see and comment on his performance.

\subsubsection{Obtain a different viewpoint}

The outcome of this study presented that video helped the teacher in obtaining a different viewpoint. As the teacher mentioned that there was an exciting fact that this was the first time for the teacher to watch his performance along with his teaching experiences. The teacher mentioned that after observing himself in the video, the teacher has different perspective on his performances. The teacher noticed that he implemented the teacher's center in the entire video. Also, the teacher demonstrated that video facilitated him to realize that there are many things that needed to be improved as the teacher wrote in his journal reflective that.

"After watching my video, I felt that there are many parts that needed to be enhanced. I realized that I still applied to the teacher center in my video (Reflective Journal Lines, 1-2).

"From the video, I realized how important the teaching method is. Because my teaching method is still on the teachers' center, then, I would implement the student's center approach for the next performance." (Interview Lines 73-76)

\subsubsection{Concerned on specific aspects}

The teacher mentioned that the valuable part from the video was he can concern on specific aspects. As the teacher indicated that he focused on his teaching method, the ability of his students, and the interaction in the classroom. The teachers realized about his teaching approach which involves the teachers' center in the classroom. Furthermore, the teacher emphasized that he noticed the differences in students' competencies while working in group 
discussion. Despite this, the video presented great content to assist the teacher in concern on the specific aspects. For instance, the teacher pointed out. 71)"

"My teaching method is still the teacher center, not the student center. (Interview Line

"In the video, I created a group discussion with random selection. As a result, the video presented me about students' personality when working in the group discussion. I noticed the students who have capabilities and students who lack capabilities in working the task. So, I can categorize them.” (Interview Lines 220-224

This study conducted to explore the perceptions of English as a foreign language (EFL) in-service teacher after watching his teaching video recording. The result of this study revealed that video-based reflection is a valuable component as self-evaluation to assist the teacher to be aware in the teaching program. Reflecting through video helped the teacher to gain a new perspective and identify the strengths and weakness of the teacher in details. These outcomes appear to be consistent with Tripp \& Rich, (2012), who described that viewing of the video supported the teachers to see the specific part and the progress that improved in the teaching. These results agree with the result of the previous study, in which Baecher et al., (2013) indicated that observing the teaching video involved in receiving the teachers more aware of assessing and preparing themselves for the future teaching.

\subsection{Implementing Ideas}

The next section considers implementing the ideas after analyzing the teaching performance from the video. The outcome revealed that video presented the real situations which have a beneficial influence on observing the teacher's performance. Throughout this point, the teacher declared such they see the real situation, and they can see it in multiple times to convince the teacher about his competencies and limitations in teaching. Overall, the video presented the valuable insight which generated the teacher to change his thought to develop teaching methodology, students' worksheet, and learning media to create fun learning. It provided in this following section.

\subsubsection{Real situations}

The teacher was asked about having a reflection during the teaching program. Then, the teacher mentioned that he perceived the teacher's feedback as the evaluation. Unfortunately, the teacher declared that the feedback was great, but he could not see the real situations. In addition, the teacher compared the teacher's feedback and video-based reflection, and the result yielded that video-based reflection was an essential element because every area can be seen as real situations. The teacher indicated that watching his performance in a video like mirroring themselves because he watches his performance with own eye. As the teacher declared.

"I found enormous differences. For instance, when reflecting by supervisor' feedback, we could achieve the result directly, but we could not see the real. (Interview Lines 134-135)

\subsubsection{Observing in multiple times}

The value of reflecting through video is that the video can be watched multiple times, which is the function to reach more something that needs to be identified. Besides, the teacher declared that a sign from the video that it can be an archive for us in the next time, and we can play it multiple times to see our performance. Thus, the teacher declared one of the benefits of reflecting through a video that he could compare his current performance with the previous to 
comprehend the progress in the teaching process in order to reduce the similar errors. For instance, the teacher confirmed.

"Well, in my belief, using video is more efficient. In order we can play it multiple times, it could be an archive for us." (Interview Lines 139-140)

"Overall, we can see the progress in each semester, year, or specific time to view it anymore. So, we prepared to decrease the same mistakes because we already identified earlier." (Interview Lines 142-144)

Afterward, this study examined the influence of video-based reflection to improve teaching skills. This study has a conclusively huge purpose of developing the teacher quality in the next teaching sessions which has similar objectives with the previous studies such as [4], [5], [16], which focus on developing teachers quality in the teaching process. Hence, it could credibly be assumed that video-based reflection assisted the teacher in developing the teaching quality. As mentioned previously, the teacher showed proof of the improvement. The outcome was supported by [17] who informed that there was a significant proof that video enhances the teachers' development in observing the classroom interaction. Overall, videobased reflection might positively impact for enhancing professional development on teachers.

\section{Conclusion}

Indeed, several limitations of the current study should be noted. First, this study has only engaged an EFL teacher in order to describe the teacher's perception of watching his teaching video in detail. Afterward, this study identified the impact of video-based reflection on improving teaching. Consequently, this study has shown that teaching skills can be developed as long as the teachers have a strong willingness to improve themselves. This study has attempted to enrich the literature on EFL teacher education in Indonesia by examining essential concerns in undertaking the teaching sessions. It would be interesting for further study to evaluate the video with the supervisor in order to achieve in-depth feedback.

\section{References}

[1] K. Lebak, "International and Multidisciplinary Perspectives Using video-supported reflection in peer groups to increase instructional effectiveness instructional effectiveness," Reflective Pract., vol. 3943, no. January, pp. 1-18, 2017.

[2] D. A. Schön, Educating the reflective practitioner: Toward a new design for teaching and learning in the professions. San Francisco, CA, US: Jossey-Bass., 1987.

[3] J. José, M. Marcos, E. Sánchez, and H. Tillema, "Teacher reflection on action : what is said ( in research ) and what is done (in teaching )," vol. 10, no. 2, pp. 191-204, 2009.

[4] T. R. Tripp and P. J. Rich, "The in fl uence of video analysis on the process of teacher change," Teach. Teach. Educ., vol. 28, no. 5, pp. 728-739, 2012.

[5] M. Kleinknecht and J. Schneider, "What do teachers think and feel when analyzing videos of themselves and other teachers teaching ?," Teach. Teach. Educ., vol. 33, pp. 13-23, 2013.

[6] L. Baecher, S. C. Kung, A. M. Jewkes, and C. Rosalia, "The role of video for selfevaluation in early field experiences," Teach. Teach. Educ., vol. 36, pp. 189-197, 2013.

[7] J. Bell, Doing your research project, Fifth Edit. New York: Open University Press, 2010.

[8] O. C. Robinson, "Qualitative Research in Psychology Sampling in Interview-Based Qualitative Research: A Theoretical and Practical Guide A Theoretical and Practical 
Guide," vol. 0887, 2014.

[9] S. Zulaiha and H. Mulyono, "Preservice EFL teachers ' talk during a teaching practicum at a lower secondary school : A report on video-stimulated reflection ( VSR )," vol. 6, no. 1, pp. 44-60, 2018.

[10] J. L. Endacott, "Using Video-Stimulated Recall to Enhance Preservice-Teacher Reflection Using Video-Stimulated Recall to Enhance,” vol. 9243, no. March, 2016.

[11] T. Christ et al., "Evaluating the use and impact of lecture recording in undergraduates: Evidence for distinct approaches by different groups of students," Teach. Teach. Educ., vol. 60, no. 1, pp. 311-326, 2017.

[12] R. B. Hourani, "International and Multidisciplinary Perspectives Pre-service Teachers 'Reflection : Perception, Preparedness and Challenges," vol. 3943, 2013.

[13] E. Burhan-horasanl and D. Ortaçtepe, "Re fl ective practice-oriented online discussions : A study on EFL teachers ' re fl ection-on, in and for-action," vol. 59, pp. 372-382, 2016.

[14] S. Aydin, "A Qualitative Research on Foreign Language Teaching Anxiety A Qualitative Research on Foreign Language Teaching Anxiety," vol. 21, no. 4, pp. 629-642, 2016.

[15] V. Braun and V. Clarke, "Using thematic analysis in psychology Using thematic analysis in psychology," vol. 0887, no. 2006, 2008.

[16] L. Baecher, "The impact of video review on supervisory conferencing," vol. 29, no. 2, pp. 153-174, 2015.

[17] B. Marsh and N. Mitchell, "Teacher Development: An international journal of teachers ', professional development The role of video in teacher professional development," no. September 2014, pp. 37-41.

\section{Appendix.}

A. Guidelines for reflective journal adapted from [4], [5]

1. How did you feel while watching the teaching scene?

2. What did you notice about the situation?

3. To what extent could you put yourself in the teaching situations?

4. What changes will you implement in the next teaching sessions?

B. Semi-structured interview adapted from several studies, such as [4], [12]-[14]

1. What does reflection mean to you?

2. How did video-based reflection influence the changes your teaching?

3. As you reflect over the period, what were some of your most outstanding learning moments throughout your reflection?

What were the problems during the process in these activities? What can you do to overcome the problems? 